\title{
In vitro assessment of gastrointestinal tract (GIT) fermentation in pigs: Fermentable substrates and microbial activity
}

\author{
Barbara A. WilliAmS ${ }^{\text {a* }}$, Marlou W. BosCH ${ }^{\mathrm{a}}$, Ajay AwATI ${ }^{\mathrm{a}}$, \\ Sergey R. KONSTANTINOV ${ }^{\text {, Hauke SMIDT }}{ }^{\mathrm{b}}$, Antoon D.L. AKKERMANS ${ }^{\mathrm{b}}$, \\ Martin W.A. VERSTEGEN ${ }^{\mathrm{a}}$, Seerp TAMMINGA ${ }^{\mathrm{a}}$ \\ a Wageningen University, Animal Nutrition Group, Marijkeweg 40, 6709 PG Wageningen, \\ The Netherlands \\ b Wageningen University, Laboratory of Microbiology, H. van Suchtelenweg 4, 6703 CT Wageningen, \\ The Netherlands
}

(Received 10 May 2004; accepted 14 March 2005)

\begin{abstract}
Recently, it has become apparent that GIT fermentation is not only of interest for ruminant animals, but also for monogastrics. While it is now widely accepted that the fermentation process and its resultant end-products can have important influences on animal health, little is known about the microbiological and immunological processes involved. In terms of animal health, most interest at the moment is focussed on those moments in animals' lives when they are faced with sudden changes resulting in stress. The period of weaning in piglets is a typical example of this. The most easily accomplished and appropriate way to influence GIT fermentation processes is that of dietary intervention. This is reflected by the widespread interest in so-called pre- and pro-biotics. Given the complexities of the interactions occurring in the animal itself, it is hardly surprising that in vitro techniques are being widely used: firstly to examine potential substrates for their fermentability and possible inclusion in diets, and secondly, to assess changes in the microbial populations in response to these substrates. This paper will review the techniques currently in use for these two aspects of monogastric fermentation, and provide examples of their use.
\end{abstract}

gastro-intestinal tract / fermentation / in vitro / microbial activity / prebiotic

Résumé - Évaluation in vitro des fermentations dans le tube digestif : substrats fermentescibles et activité microbienne. Il est apparu récemment que les fermentations dans le tube digestif présentent un intérêt non seulement pour les ruminants mais aussi pour les monogastriques. Alors qu'il est maintenant bien accepté que les processus fermentaires et les produits terminaux résultants peuvent avoir des effets sur la santé animale, peu de choses sont connues concernant les processus microbiologiques et immunitaires impliqués. En termes de santé animale, le principal intérêt du moment est focalisé sur ces périodes de la vie animale pendant lesquelles les animaux sont confrontés à des changements soudains conduisant à une situation de stress. Le sevrage chez le porcelet est un exemple typique de ces périodes critiques d'élevage. La manière la plus simple et la plus appropriée

\footnotetext{
* Corresponding author: barbara.williams@wur.nl
} 
d'influencer les processus fermentaires digestifs est la voie alimentaire. Ceci est reflété par l'intérêt très large que représentent les prébiotiques et les probiotiques. Étant donné la complexité des interactions intervenant dans l'animal lui-même, il n'est pas surprenant que des techniques in vitro aient été largement utilisées : premièrement pour examiner les substrats potentiels pour leur fermentescibilité et leur introduction possible dans les régimes et, deuxièmement, pour évaluer les changements dans les populations microbiennes en réponse à ces substrats. Ce papier passe en revue les techniques actuellement utilisées pour ces deux aspects des fermentations chez le monogastrique, et apporte des exemples de leur utilisation.

tube digestif / fermentation / in vitro / activité microbienne / prébiotique

\section{INTRODUCTION}

Fermentation occurring in the monogastric gastrointestinal tract (GIT) is increasingly being recognised as having an important influence on health both of the GIT itself, and also of the host animal. From the point of view of GIT health, it is recognised that fermentation is important for gut motility, the improvement of energy yield, the production of vitamins, and the stimulation of gut immunity [6]. The production of short chain fatty acids (SCFA) is specifically thought to make an important contribution to the energy metabolism of monogastrics [6]. The SCFA are also involved in prevention of diarrhoea (water and $\mathrm{Na}^{+}$absorption) [37], $\mathrm{pH}$ control within the GIT, and defence against pathogens (colonisation resistance). For example, it has been shown that SCFA inhibit the growth of salmonella [43].

However, the fermentation process is extremely complex, and not all fermentation processes are positive. On the contrary, some processes can have a negative effect on health. The type of fermentation that takes place is determined by many factors including the host, its microflora, and the interactions which take place between them. Furthermore, the diet of the animal can also affect the major fermentation patterns, such as whether the fermentation is predominantly of carbohydrates or protein.

With the forthcoming ban on the addition of antibiotics as growth promoters in piglet feeds, there is great interest in the GIT microbial community and its activities, and more specifically, in how the diet can be modified to steer the fermentation towards appropriate end-products. To this end, a large number of potential feedstuffs need to be tested. Moreover, it is largely unknown how GIT microbial populations react and interact in response to certain inputs (i.e. feed ingredients).

No in vitro technique could ever surpass or even equal the results that can be obtained from a living animal, most particularly in terms of assessing its health and well-being. However, almost as a side-issue of the search for antibiotic replacements, there is a sudden and urgent need for techniques which can:

- test large numbers of ingredients of potential interest for addition to diets, and

- indicate the changes in GIT microbial activity which could result from the addition of those ingredients.

The purpose of this paper is to indicate the in vitro techniques currently available for these two purposes, and where possible, indicate the extent to which their results have been reflected in in vivo results.

\section{THE GIT MICROBIAL COMMUNITY}

The digestive tract is colonised soon after birth by a variety of microorganisms. The development of a normal microbial community in young animals is affected by the use of excessive hygiene, antibiotic therapy, and perhaps most important of all, stress. However, the bacteria of the GIT are also affected by the nutrition of the host, and its environment. Problems, or delays in the 
development of a normal microflora, can have dramatic effects on the development of the immune system, particularly in the event of an imbalance between pathogens and non-pathogens.

In a healthy adult animal, the GIT microbial community is an extremely complex system, comprising more than 400 species of bacteria ( $>10^{11}$ cells per $g$ digesta contents). Not surprisingly, there is a very complex series of interactions and competition going on between these bacteria, which are still poorly understood [6].

\subsection{Carbohydrate fermentation}

In human nutrition, prebiotics (mainly fermentable carbohydrates), must, by definition [11], be undegradable by mammalian enzymes, and are therefore potentially available for fermentation by micro-organisms living in the GIT (in humans, mainly the colon). The amount and composition of substances reaching the large intestine can be readily modified by diet and in terms of bacterial substrates, it is probably this carbohydrate fraction (oligosaccharides, nonstarch polysaccharides (NSP), and starches), which is the most important [25]. Some of these fractions may be soluble (e.g. oligosaccharides). It is thought that these fermentable carbohydrates affect fermentation by stimulating the growth or metabolism of specific bacterial species, which are potentially beneficial for health. Such fermentation leads to the production of mainly straight-chain SCFA (e.g. lactic, acetic, propionic, and butyric acids), and the use of ammonia and other nitrogenous compounds, which are taken up by the cells and used for bacterial growth. It is known that the straight-chain fatty acids can be beneficial for health. For example, it is well known that the presence of the SCFA will lead to a drop in $\mathrm{pH}$ that can have a negative effect on some potentially pathogenic bacteria. In terms of host metabolism, it has been shown that acetate is metabolised in the brain [20] and muscle [22], while butyrate is an essential energy source for colonocytes [36].
Some specific carbohydrate compounds can have more specific effects on specific microbial species. For example, substances such as mannose [32], and galactan [26] have been found to block the adherence of pathogenic E. coli strains, though the exact mechanism for this action is still poorly understood.

\subsection{Protein fermentation}

In humans, the proximal colon contains food residues and other substrates from the small intestine, and is usually rich in both carbohydrates and proteins. Fermentation is thought to be the most active here, due to the findings that there is generally a higher SCFA concentration and more acidic $\mathrm{pH}$. However, as the digesta move more distally, the fermentable carbohydrate fraction is reduced, and hence proteolytic microorganisms become more active, while saccharolytic populations are reduced [23]. Protein is always available along the whole tract in the form of non-degradable and endogenous sources. The end-products of protein fermentation are the following: branched-chain SCFA, $\mathrm{NH}_{3}$, and compounds such as phenols, indoles and amines. These latter products have all been shown to have potentially negative effects on host health [4]. The detection of branched-chain fatty acids, which are formed by the metabolism of branched-chain amino acids such as valine, leucine, and iso-leucine [23] can act as a useful marker to detect the proportion of protein fermentation occurring both in vivo and in vitro.

\section{IN VITRO TECHNIQUES TO EVALUATE FEED INGRE- DIENTS FOR THEIR POTENTIAL FERMENTABILITY}

When considering certain feed ingredients for inclusion in diets, it is important to know not only that it is not degradable by mammalian enzymes, but also that it is, indeed, fermentable. Solubility, as such, is 
not an indicator of fermentability. It is sometimes falsely assumed that the solubility of a particular carbohydrate is directly linked to being fermentable. It is therefore advisable to screen potential feed ingredients for their fermentability before being added to animal diets to improve GIT health. In fact, ideally, information should be available concerning the extent and pathway of fermentation for a specific ingredient, i.e. the end-products which are formed, and the rate at which it is fermented. The availability of in vitro approaches for the assessment of these parameters would then allow for the examination of a range of different materials, before making a choice for inclusion in an in vivo study. In some cases, a pre-treatment with in vitro digestive enzymes can also be included [1].

In vitro techniques to estimate fermentability vary widely in their complexity, and in how many of the above three parameters can be assessed.

\subsection{Batch cultures}

The simplest in vitro fermenters are static batch cultures, whereby the test ingredient (substrate) is incubated within an appropriate medium containing an inoculum of either digesta or faeces. The fermentation is allowed to continue for (usually) 24-72 hours, and sampling takes place for various end-products. These techniques usually have the advantage that one can screen a range of products in a comparatively short time, and that only small amounts of substrate are required.

\subsubsection{Glass fermenters}

Macfarlane et al. [23] attempted to quantify protein fermentation using an in vitro batch system culture in which they measured the production of branched-chain fatty acids over a 72 hour period. They used four $1 \mathrm{~L}$ glass fermenters containing $250 \mathrm{~mL}$ medium, which were inoculated with washed bacteria from three human individuals. All procedures were conducted anaerobically. They were sampled for branched-chain fatty acid production, and then they compared these values with those taken from sudden death victims to compare in vitro and in vivo results. In terms of predicting the amount of branched-chain acids that one would expect from an estimate of the protein entering the large intestine, the in vitro technique gave a good prediction of what was found in vivo.

\subsubsection{Cumulative gas production technique}

The measurement of gas is essentially the measurement of a fermentation endproduct. Whether carried out manually [42], or with one of the new automated systems (e.g. [5]), the principle is the same. The measurement of accumulating gas in vitro is related to the kinetics of the fermentation process, and in so doing, allows for the calculation of fermentation rates. An example is shown in Figure 1, comparing the cumulative gas production of fructo-oligosaccharides (FOS) and sugarbeet pulp (SBP).

To some extent, depending of course upon the GIT transit times found in the host, these rates may give an indication of where the ingredient may actually be fermented in the GIT. This is one area in which there are important differences between pigs and humans. There seems to be very little fermentation occurring in the human small intestine, while in the pig, particularly for rapidly fermentable carbohydrates, there can be quite an extensive fermentation occurring. Short-chain fatty acid production and organic matter degradability (OMD) are usually measured at the end of the fermentation process as well. The resultant gas profiles generated in vitro are then fitted to certain equations, which have been developed for the purpose.

The cumulative gas production technique is being used in our laboratory to test large numbers of different carbohydrates, with particular attention being paid to the 


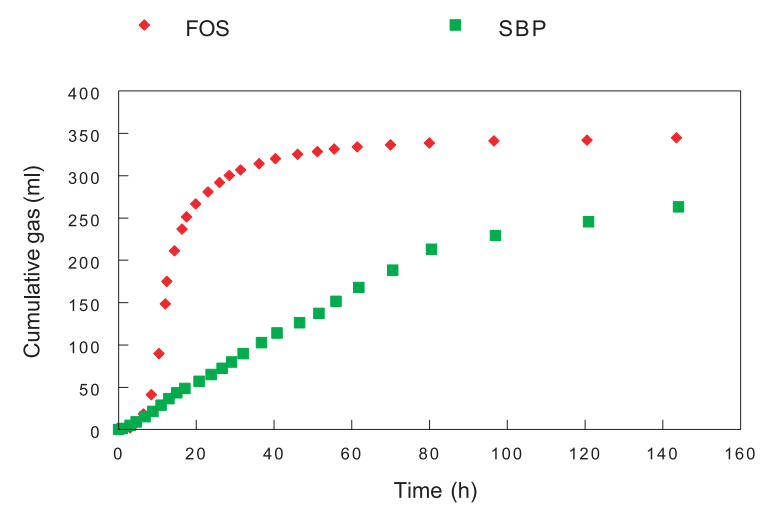

Figure 1. In vitro cumulative gas production profiles of fructooligosaccharide (FOS) and sugarbeet pulp (SBP), using porcine faeces as the inoculum.

kinetics of the fermentation process [2]. By investigating the rates at which fermentation takes place, it is possible to gauge where fermentation might occur in the GIT based on known rates of passage in vivo, and so to formulate diets that will stimulate fermentation along the entire tract [48]. For example, a standard substrate (such as ileal chyme) was chosen, and small quantities of potential (pure) feed additives were added to look at the resulting shifts in end-products at the end of in vitro fermentation. The results were then used to predict what might happen in terms of fermentation in the GIT (Bauer et al., submitted) if those products were added to the animal diet.

One important disadvantage of methods using batch cultures is, however, that they are closed systems, where the amount of substrate must be limited to avoid negative feedback mechanisms coming into play.

\subsection{Semi-continuous culture}

Semi-continuous cultures are those for which medium is added and spent culture is removed at known intervals. Miller and Wolin [29] maintained a semi-continuous culture of a mixed population from the human large intestine for a period of 81 days. By feeding the culture different feed ingre- dients (including lettuce, celery and carrots), they found that the counts for different species changed, according to the ingredients given.

\subsection{Continuous culture}

According to Gibson and Fuller [10], continuous culture systems can be used to simulate intestinal conditions more closely than for batch cultures. Dilution rates and other parameters can be varied, so that optimum conditions can be maintained.

Macfarlane et al. [24] developed a model comprising three vessels aligned in a series. The first vessel contained a nutrient-rich medium, with fast transit, and acidic conditions. The second vessel was operated at intermediate conditions, and the third vessel had low levels of substrate, slower transit and neutral conditions. The theory is that the first resembles the proximal colon, the second the transverse colon, and the third the distal colon of humans. The purpose of this technique was to test certain substrates for their fermentability as they moved between the vessels, by examining both selected bacterial species and their endproducts at certain time points.

Minekus [30] described an in vitro system to simulate the stomach and small intestine 
of the gastro-intestinal tract that incorporates such parameters as peristaltic movements, transit time, $\mathrm{pH}$ and secretion as well as the addition of digestive enzymes at appropriate points. This model therefore, tested only those aspects of digestibility related to mammalian enzymes. A later model intended to simulate the large intestine [31], incorporated the fermentation aspects of the digestive process by inclusion of a faecal inoculum.

\section{TECHNIQUES TO EXAMINE THE GIT MICROBIAL COMMUNITY}

\subsection{Microbial counts vs. molecular techniques}

Various in vitro and in vivo methods have been used to evaluate feed ingredients for their potential fermentability. One common in vivo approach is to add the test ingredient to the animal diet and then use agar plates thought to be selective for specific bacterial species, in order to examine changes in those species in the digesta and faeces of the animal [17]. However, while it has been shown that the metabolic activity of the conventional microflora can be sensitive to changes in the diet [39], the species composition (according to viable counts) appears to be less affected by changes in the diet, at least with respect to the populations of the major genera.

One of the major disadvantages of traditional counts is that it is impossible to count more than eight to ten of the hundreds of species present at any one time [44]. In most cases, further identification below the genus level is only rarely carried out. It has been concluded [9] that while the strict anaerobes are absolutely necessary for the proper functioning of the large intestinal microflora, it is unlikely that only one or a few of these anaerobes are of predominant importance. Rather, each strain has to fill its own distinct ecological niche. It has even been suggested that a few key microorganisms, present in comparatively small num- bers, may have key roles to fulfil in the function of the total microflora [33]. An example of why microbial counts are not necessarily appropriate for the investigation of microflora activity as such, was reported in a study by Florent et al. [8]. They measured the effects of an oral load of nonabsorbable sugars, and failed to show any significant modification of the bacterial populations examined, which is in agreement with the findings of Finegold and Sutter [7], and Hentges [15]. However, they also pointed out that studies of bacterial enzymes, on the contrary, had revealed marked changes $[16,41]$, though the reasons for this were unclear.

There are other explanations for the discrepancies. Considerable differences between counts may occur because any single medium will not support the growth of all bacteria normally present in the gut. This is a major problem for the assessment of viable bacterial numbers in any natural environment. Colony counts of anaerobic rumen bacteria are influenced markedly by the methods and media used [14, 18]. Another source of error is the attachment of bacteria to solid particles. This is a particular problem in the GIT, where cellulolytic and other bacteria can be firmly attached to plant fragments. Further errors may arise because of clumping of bacteria. Bacteria in freshly voided swine faeces, for example, may occur as discrete pure colonies rather than as single cells [34]. For these reasons, and particularly in the case of examinations of gut health, there is now increasing interest in methods which indicate microbial activity of a whole community.

Techniques from the field of molecular biology (such as comparative sequencing and molecular probes) are increasingly being used to explore the GIT microflora [44, 49]. These techniques have the advantage that by employing universal and group-specific $16 \mathrm{~S}$ ribosomal RNA / DNA targeted probes and primers, one has a very powerful tool to gain a more complete picture of most, if not all the species present in the microbial community, 
including those which are either difficult or impossible to culture. Such techniques are leading to a complete reassessment of the structure of the GIT microflora, not only in relation to the host animal species, but also in terms of age, diet [21], health, and the genome of the host [49]. However, it is also recognised that apart from the descriptive role of these techniques, it is also important to relate them to the dynamics of GIT processes [40]. Even though such techniques cannot always identify the species of all organisms present, one can readily detect shifts in the community, in response to particular changes in their environment.

\subsection{Measurements of whole microbial population activity}

Instead of counting microorganisms, the activity of a whole mixed microbial population can also be determined by measuring microbial activity [3]. A measure of microbial activity may be obtained from production rates of microbial protein or fermentation end-products, or from turnover rates of various chemical pools that involve the microbes. When studying the metabolism of the whole gut microflora, information on the metabolic reactions performed by the individual species is often of little use. The colonic microflora of mammals is a highly complex ecosystem comprising more than 400 different microbial species. Details of the metabolism of these species in terms of available nutrients are not known. Even if they were, it would be difficult to predict whether a reaction that occurs with a pure culture in vitro would also occur when the organism is interacting with other species in vivo [38].

Growth of anaerobic bacteria under favourable conditions is directly related to the amount of ATP derived from fermentation. Hence, cell yields are a function of both the amount of substrate fermented, and of the fermentation end-products produced [3]. Measures of both substrate utilisation and end-product production can therefore be used to indicate the growth of cells and cell mass. The end-products most commonly measured include SCFA and gas. Consequently, a better approach to understanding the role of the gut microflora in nutrition and toxic events is to treat the microflora as a single entity [38] ignoring its multi-organism composition. This approach has been used with some success by a number of researchers using a variety of functional assays on faeces or gut contents ([13, 28]; Williams et al., in preparation).

For example, Robinson et al. [35] incubated contents from different areas of the pig GIT and measured the production of gas and SCFA to determine whether methanogenic activity was similar to that in humans. They discovered that it was not, but also that the measurements of SCFA were consistent with previously reported findings in vivo. They also found that the measurements for gas production, while underestimating the gas produced for the whole animal, were useful for comparative purposes. This was also found by Jensen and Jørgensen [19], in a similar study investigating the effect of dietary fibre in pig diets.

By using human faeces as an inoculum [27], it was shown that six different sources of starch, while having the same total SCFA production, differed in their rates of gas production. They thus showed that the measurements of gas production more likely reflected the fermentation rate in vivo. They therefore concluded that an in vitro assessment of the fermentative characteristics of raw starches was a useful means of evaluating the potential effects of starches on colonic function.

\subsubsection{Cumulative gas production technique}

The method of Theodorou et al. [42] which measures the kinetics of fermentation can also be used to assess the activity of microbial populations [47]. This method involves measurement of accumulating gas during fermentation, so that one obtains a picture of the kinetics of microbial activity 


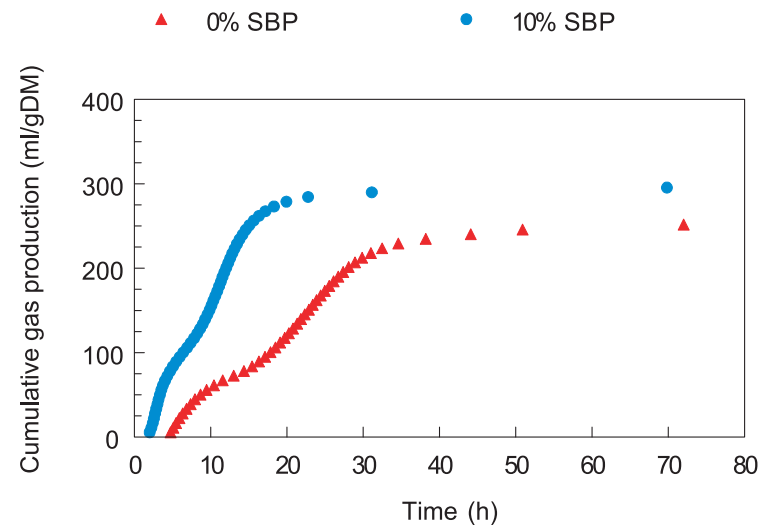

Figure 2. In vitro cumulative gas production profiles of sugarbeet pulp (10\% SBP), using faeces from newly weaned piglets after 10 days with (10\% SBP) and without SBP (\% SBP) in their diets.

of the community acting as a whole. At the end of the fermentation period, samples are taken for the measurement of SCFA and ammonia, and substrate utilisation. The technique is carried out under strictly anaerobic conditions, and is being used to examine the activity of the microflora from many different sources including different sections of the GIT of pigs [45], and the caecae of poultry [46]. By using different starting substrates, it becomes possible to look at shifts in microbial populations that are associated with the fermentation of a particular feedstuff, e.g. resistant starch, protein, or fibre [47]. For example, cumulative gas production profiles of SBP as the in vitro substrate that uses inoculum from piglets with and without that ingredient in their diets, are shown in Figure 2. The profiles show quite convincingly that pre-exposure to SBP led to a shift in the microbial activity, so that the SBP-exposed bacteria were able to ferment the in vitro material faster, but that there was little difference in the final end-products (SCFA data not shown).

Recently, this measurement of cumulative gas production was used in combination with molecular techniques such as $16 \mathrm{~S}$ rDNA-targeted denaturing gradient gel electrophoresis (DGGE) fingerprinting, and cloning and sequencing of $16 \mathrm{~S}$ rDNA, to estimate the potential prebiotic effect of certain non-digestible, fermentable feed ingredients, such as SBP. The aim was to use sequence analysis of bacterial $16 \mathrm{Sr}$ DNA to describe the effect of a diet containing non-digestible carbohydrates - fructooligosaccharide (FOS) and SBP - on the composition of the predominant faecal microbiota of weaner piglets. This was done in combination with an animal experiment and should allow one to determine whether the bacterial species selected for in vitro by the FOS and SBP, were also found in vivo (Konstantinov et al., submitted; Awati et al., submitted).

\section{CONCLUSIONS}

The GIT is a very complex system, involving interactions between the host and its microorganisms, and also between the different microbial species themselves. Therefore, it seems unrealistic to develop an in vitro system that will exactly mimic the physiological situation. However, if the shortcomings of each method are taken into account, in vitro techniques can have an 
important role to play, both in the assessment of potential feed ingredients before they are added to animal diets, and also in examining changes which have occurred in microbial populations as a result of some kind of treatment (e.g. diet). In this short review, a summary has been made of some of the techniques currently in use for these two purposes.

\section{REFERENCES}

[1] Bauer E., Williams B.A., Voigt C., Mosenthin R., Verstegen M.W.A., Impact of mammalian enzyme pretreatment on the fermentability of carbohydrate-rich feedstuffs, J. Sci. Food Agric. 83 (2003) 207-214.

[2] Bauer E., Williams B.A., Voigt C., Mosenthin R., Verstegen M.W.A., Microbial activities of faeces from unweaned and adult pigs, in relation to selected fermentable carbohydrates, Anim. Sci. 73 (2001) 313-322.

[3] Clarke R.T.J., Methods for studying gut microbes, in: Clarke R.J., Bauchop T. (Eds.), Microbial ecology of the gut, Academic Press, London, 1977, pp. 1-333.

[4] Cummings J.H., Macfarlane G.T., Drasar B.D., The gut microflora and its significance, in: Whitehead R. (Ed.), Gastrointestinal Pathology, Churchill-Livingstone, Edinburgh, UK, 1989, pp. 201-219.

[5] Davies Z.S., Mason D., Brooks A.E., Griffith G.W., Merry R.J., Theodorou M.K., An automated system for measuring gas production from forages inoculated with rumen fluid and its use in determining the effect of enzymes on grass silage, Anim. Feed Sci. Technol. 83 (2000) 205-221.

[6] Ewing W.N., Cole D.J.A., The Living Gut: An Introduction to Micro-organisms in Nutrition, Context, Dungannon, Ireland, 1994.

[7] Finegold S.M., Sutter V.L., Faecal flora in different populations with special reference to diet, Am. J. Clin. Nutr. 31 (1978) S116-S122.

[8] Florent C., Flourie B., Leblond A., Rautureau M., Bernier J.-J., Rambaud J.-C., Influence of chronic lactulose ingestion on the colonic metabolism of lactulose in man (an in vivo study), J. Clin. Invest. 75 (1985) 608-613.

[9] Freter R., Factors affecting the microecology of the gut, in: Fuller R. (Ed.), Probiotics - The Scientific Basis, Chapman and Hall, London, 1992, pp. 111-114.
[10] Gibson G.R., Fuller R., Aspects of in vitro and in vivo research approaches directed toward identifying probiotics and prebiotics for human use, J. Nutr. 130 (2000) 391S-395S.

[11] Gibson G.R., Roberfroid M.B., Dietary modulation of the human colonic microbiota: introducing the concept of prebiotics, J. Nutr. 125 (1995) 1401-1412.

[12] Gibson S.A.W., McFarlane C., Hay S., McFarlane G.T., Significance of microflora in proteolysis in the colon, Appl. Environ. Microbiol. 55 (1989) 679-683.

[13] Goldin B.R., Gorbach S.L., The relationship between diet and rat faecal enzymes implicated in colon cancer, J. Nat. Cancer Institute 57 (1976) 371-375.

[14] Grubb J.A., Dehority B.A., Variation in colony counts of total viable anaerobic rumen bacteria as influenced by media and cultural methods, Appl. Environ. Microbiol. 31 (1976) 262-267.

[15] Hentges D.J., Faecal flora of volunteers on controlled diets, Am. J. Clin. Nutr. 31 (1978) S123-S124.

[16] Hill M.J., Bacterial adaptation to lactase deficiency, in: Delmont J.C. (Ed.), Milk intolerance and rejection, Karger, Basel., 1983, pp. 22-26.

[17] Houdijk J.G.M., Hartemink R., Verstegen M.W.A., Bosch M.W., Effects of dietary nondigestible oligosaccharides on microbial characteristics of ileal chime and faeces in weaner pigs, Arch. Anim. Nutr. 56 (2002) 297-307.

[18] Hungate R.E., The Rumen and its Microbes, Academic Press, London and New York, 1966.

[19] Jensen B.B., Jørgensen H., Effect of dietary fibre on microbial activity and microbial gas production in various regions of the gastrointestinal tract of pigs, Appl. Environ. Microbiol. 60 (1994) 1897-1904.

[20] Juhlen-Dannfelt A., Ethanol effects of substrate utilization by the human brain, Scand. J. Cli. Lab. Inv. 37 (1977) 443-449.

[21] Konstantinov S.R., Zhu W.-Y., Williams B.A., Tamminga S., de Vos W.M., Akkermans A.D.L., Effect of fermentable carbohydrates on piglet faecal bacterial communities as revealed by denaturing gradient gel electrophoresis analysis of $16 \mathrm{~S}$ ribosomal DNA, FEMS Microbiol. Ecol. 43 (2003) 225-235.

[22] Lundqvist F., Sestoft L., Damggard S.E., Clausen J.P., Trap-Jensen J., Utilization of acetate in the human forearm during exercise 
after ethanol ingestion, Clin. Invest. 52 (1973) 3231-3235.

[23] Macfarlane G.T., Gibson G.R., Beatty E., Cummings J.H., Estimation of short-chain fatty acid production from protein by human intestinal bacteria based on branched-chain fatty acid measurements, FEMS Microbiol. Ecol. 101 (1992) 81-88.

[24] Macfarlane G.T., Macfarlane S., Gibson G.R., Validation of a three-stage compound continuous culture system for investigating the effect of retention time on the ecology and metabolism of bacteria in the human colonic microbiota, Microb. Ecol. 35 (1998) 180-187.

[25] Mathers J.C., Annison E.F., Stoichiometry of polysaccharide fermentation in the large intestine, in: Samman S., Annison G. (Eds.), Dietary Fibre and Beyond-Australian Perspectives, Nutrition Society of Australia Occasional Publications, Vol. 1, 1993, pp. 123-135.

[26] Mathew A.G., Sutton A.L., Scheidt A.B., Patterson J.A., Kelly D.T. Meyerholz K.A., Effect of galactan on selected microbial populations and $\mathrm{pH}$ and volatile fatty acids in the ileum of the weanling pig, J. Anim. Sci. 71 (1993) 1503-1509.

[27] McBurney M.I., Cuff D.J., Thompson L.U., Rates of fermentation and short chain fatty acid and gas production of six starches by human faecal microbiota, J. Sci. Food Agric. 50 (1990) 79-88.

[28] Midtvedt T., in: Hattori T., Ishida Y., Maruyama Y. (Eds.), Recent Advances in Microbial Ecology, Japan Scientific Societies Press, Tokyo, 1989, pp. 515-519.

[29] Miller T.L., Wolin M.J., Fermentation by the human large intestinal microbial community in an in vitro semicontinuous culture system, Appl. Environ. Microbiol. 42 (1981) 400-407.

[30] Minekus M., Development and validation of a dynamic model of the gastrointestinal tract, $\mathrm{PhD}$ Thesis, University of Utrecht, The Netherlands, 1998.

[31] Minekus M., Smeets-Peeters M., Bernalier A., Marol-Bonnin S., Havenaar R., Marteau P., Alric M., Fonty G., Huis in 't Veld J.H.J., A computer-controlled system to simulate conditions of the large intestine with peristaltic mixing, water absorption and absorption of fermentation products, Appl. Microbiol. Biotechnol. 53 (1999) 108-114.

[32] Ofek I., Mirelman D., Sharon N., Adherence of Escherichia coli to human mucosal cells mediated by mannose receptors, Nature 265 (1977) 623-625.
[33] Prins R.A., Stewart C.S., Microbial interactions in the rumen, in: Proceedings of the joint RRI-INRA Rumen Microbiology Symposium, Aberdeen, Scotland, March 20-21 (1997) 1-3.

[34] Rall G.D., Wood A.J., Wescott R.B., Dommert A.R., Distribution of bacteria in feces of swine, Appl. Microbiol. 20 (1970) 789-792.

[35] Robinson J.A., Smolenski W.J., Ogilvie M.L., Peters J.P., In vitro total-gas, $\mathrm{CH}_{4}, \mathrm{H}_{2}$, volatile fatty acid, and lactate kinetics studies on luminal contents from the small intestine, cecum and colon of the pig, Appl. Environ. Microbiol. 55 (1989) 2460-2467.

[36] Roediger W.E.W., Utilization of nutrients by isolated epithelial cells of the rat colon, Gastroenterology 83 (1982) 424-429.

[37] Roediger W.E.W., Short-chain fatty acids as metabolic regulators of ion absorption in the colon, Acta Vet. Scand. 86 (1989) 116-125.

[38] Rowland I.R., Metabolic interactions in the gut, in: Fuller R. (Ed.), Probiotics - The Scientific Basis, Chapman and Hall, London, 1992, pp. 29-53.

[39] Rowland I.R., Wise A., The effect of diet on the mammalian flora and its metabolic activities, CRC Crit. Rev. Toxicol. 16 (1985) 31-103.

[40] Sharp R., Ziermer C.J., Stahl D.A., A phylogenetic assessment of bovine rumen methanogens during perturbation by acidosis, in: Proceedings of the joint RRI-INRA Rumen Microbiology Symposium, Aberdeen, Scotland, March 20-21, 1997, p. 10

[41] Simon G.L., Gorbach S.L., Intestinal flora in health and disease, Gastroenterology 86 (1984) 174-193.

[42] Theodorou M.K., Williams B.A., Dhanoa M.S., McAllan A.B., France J., A simple gas production method using a pressure transducer to determine the fermentation kinetics of ruminant feeds, Anim. Feed Sci. Technol. 48 (1994) 185-197.

[43] Van der Wielen P.W.J.J., Biesterveld S., Lipman L.J.A., van Knapen F., Inhibition of a glucoselimited sequenced fed-batch culture of Salmonella enterica serovar enteritidis by volatile fatty acids representative of the ceca of broiler chickens, Appl. Environ. Microbiol. 67 (2001) 1979-1982.

[44] Vaughan E.E., Schut F., Heilig H.G.H.J., Zoetendahl E.G., de Vos W.M., Akkermans A.D.L., A molecular view of the intestinal ecosystem, Curr. Issues Intestin. Microbiol. 1 (2000) $1-12$ 
[45] Williams B.A., Bosch M., Houdijk J., van de Camp Y., Differences in potential fermentative capablilities of four sections of porcine digestive tract, in: Proceedings of the 48th EAAP meeting, Vienna, Austria, 1997, p. 195.

[46] Williams B.A., Van Osch L.J.M., Kwakkel R.P., Fermentation characteristics of the caecal contents of broiler chickens fed fine- and coarse particle diets, in: WPSA Spring Meeting of the UK Branch, Scarborough, UK, 1997, p. 49.

[47] Williams B.A., Tamminga S., Verstegen M.W.A., Fermentation kinetics to assess microbial activity of gastro-intestinal micro- flora, in: Proceedings of the symposium "Gas Production: Fermentation kinetics for feed evaluation and to assess microbial activity", Wageningen, Netherlands, 2000, pp. 97-100.

[48] Williams B.A., Verstegen M.W.A., Tamminga S., Fermentation in the large intestine of singlestomached animals and its relationship to animal health, Nutr. Res. Rev. 14 (2001) 207-227.

[49] Zoetendaal E.G., Akkermans A.D.L., de Vos W.M., Temperature gradient gel electrophoresis analysis of $16 \mathrm{~S}$ rRNA from human faecal samples reveals stable and host-specific communities of active bacteria, Appl. Environ. Microbiol. 64 (1998) 3854-3859. 